\title{
Modelling highly deformable metal extrusion using SPH
}

\author{
Mahesh Prakash • Paul W. Cleary
}

Received: 23 May 2014 / Revised: 20 January 2015 / Accepted: 23 January 2015 / Published online: 4 February 2015

(C) OWZ 2015

\begin{abstract}
Computational modelling is often used to reduce trial extrusions through accurate defect prediction. Traditionally, metal extrusion is modelled using mesh based finite element methods. However, large plastic deformations can lead to heavy re-meshing and numerical diffusion. Here we use the mesh-less smoothed particle hydrodynamics method since it allows simulation of large deformations without re-meshing and the tracking of history dependent properties such as plastic strain making it suitable for defect prediction. The variation in plastic strain and deformation for aluminium alloy in a cylindrical 3D geometry with extrusion ratio and die angle is evaluated. The extrusion process is found to have three distinct phases consisting of an initial sharp rise in extrusion force, a steady phase requiring constant force and terminating in a sharp decline in force as metal is completely extruded. Deformation and plastic strain increased significantly with extrusion ratio but only moderately with die angle. Extrusion force increased by $150 \%$ as the extrusion ratio increased from 2:1 to 4:1 but had only a marginal change with die angle. A low strain zone in the centre of the extruded product was found to be a function of extrusion ratio but was persistent and did not vary with die angle. Simulation of a complex 3D building industry component showed large variations in plastic strain along the length of the product at two scales. These were due to change in metal behaviour as extrusion progressed from phase 1 to phase 2. A stagnation zone at the back of the die was predicted that could lead to the "funnel" or "pipe" defect.
\end{abstract}

Keywords Cold extrusion - Solid deformation - Strain . Mesh-free method $\cdot$ Defect prediction $\cdot$ SPH

M. Prakash $\cdot$ P. W. Cleary $(\bowtie)$

CSIRO Digital Productivity Flagship, Clayton, VIC 3169, Australia

e-mail: paul.cleary@csiro.au

\section{Introduction}

Extrusion can be defined as the production of a part of a desired shape by forcing a solid billet to flow through a die. Extrusion is often used in making automotive and building hardware parts where high strength and close tolerances are required. It is also used for extruding plastics and many well known food products. The advantages of modelling extrusion include:

- Ability to verify empirical knowledge

- Prediction of defects in extruded product

- Reduction in the number of trial die designs

- Improvements to existing die design through optimization

- Evaluation and modification of existing die design for a new extrusion material.

Modelling of extrusion and similar metal forming processes have so far largely been carried out using the mesh based finite element method (FEM). Lim and Dunne [23] used the FE software ABAQUS to investigate the central burst defect formation during extrusion. Komori [21] used an in-house developed finite element code to investigate the mechanics of ductile fracture in bulk metal forming processes. Saanouni et al. [31] investigated the occurrence of discontinuous central bursting during cold extrusion using Forge2 FE. Tiernan et al. [32] used the ELFEN finite element code to simulate the cold extrusion of aluminium. In all these cases the simulations were either in 2D or 2D axi-symmetric. D. C. Chen et al. [5] performed 3D FE simulations of cold extrusion using the DEFORM3D software. They used a relatively simple conical geometry and a modest extrude ratio of 2.04. More recently [4] used 3D FE modelling to optimise the flow balance in isothermal extrusion of aluminium. This study was performed to reduce variations in the shape and mechanical 
properties of the extruded product. A large extrusion ratio of 27:1 was used for the extruded product. A 2D axi-symmetric model was assumed for the numerical simulations. The real product shape could however become non-axisymmetric due to flow imbalances occurring during extrusion. Large plastic deformations in the metal during extrusion for large extrude ratios can lead to heavy re-meshing requirements for FEM methods as described in [32]. This can lead to inaccuracies in the solution and numerical diffusion.

Mesh free methods can model very large deformations since the connectivity among nodes is generated as part of the computation and is inherently transient in nature. The mesh free smoothed particle hydrodynamics (SPH) method has in the past been successfully applied to several industrial metal forming processes involving liquid metal including gravity die casting by [19], high pressure die-casting by [7] and [8], direct chill casting by [3] and ingot casting by [30] . In order to address the issue of re-meshing in regions of high deformation [16] developed a blended FE/SPH method and applied it to a simple metal forming problem. Alfaro et al. [1] developed a natural element method (NEM) which falls in the category of mesh less methods. This alternative technique was used to simulate simple 2D forming processes involving large displacements. Alfaro et al. [2] then extended the NEM method to perform 3D simulation of aluminium extrusion in simple geometries assuming it to be a rigid plastic material. Xiong and Martins [34] developed and applied the reproducing kernel particle method for simulating bulk material forming processes. Around the same time [9] used SPH in $2 \mathrm{D}$ to explore its ability to simulate metal forming processes such as extrusion and forging. It was shown that the particle based nature of the method gives it the ability to track history dependent properties such as surface oxide formation and plastic strain on a node by node basis even during very large deformations. Cleary and Das [11] provided a range of examples of SPH usage for solid mechanics. Cleary [12] used an elastoplastic SPH method in two dimensions to examine deformation during projective-wall collision. Cleary et al. [13] used the same SPH solid mechanics formulation in three dimensions to predict forging behaviour and defects related to incomplete filling of the die and flashing due to excessive material build up. More recently, [25] applied the element free Galerkin method to simulate metal forming in arbitrary shaped 3D dies using a rigid/visco-plastic assumption.

In this paper we extend the study in [9] and explore the ability of SPH to model metal extrusion in a 3D geometry for a range of the control parameters, extrusion ratio and die angle. Variations in plastic strain level, metal deformation pattern and maximum extrusion force are compared. The extrusion process is shown to consist of three distinct phases starting with a sharp increase in the extrusion force, followed by a central steady phase requiring constant force and terminating in a sharp decline in the force as the end of the billet approaches the die exit. The relationship between control parameters and occurrence of extrusion defects such as chevron and chatter cracks is discussed. We then apply the method to simulate the extrusion of a metallic building industry component to demonstrate the ability of SPH to handle extrusion of complex shaped parts in three dimensions.

\section{The SPH Method for elastoplastic deformation}

For metal extrusion we use the elastic dynamics equations presented in [17]. The method was modified by [9] to include plastic deformation during the extrusion process using the radial return plasticity model of [33]. Only a summary of the SPH method applied to elastic materials is presented here. For details of the SPH interpolation method see [27].

\subsection{Continuity equation}

The SPH continuity equation is from [27]:

$\frac{d \rho_{a}}{d t}=\sum_{b} m_{b}\left(\mathbf{v}_{a}-\mathbf{v}_{b}\right) \cdot \nabla W_{a b}$,

where $\rho_{a}$ is the density of particle a with velocity $\mathbf{v}_{\mathrm{a}}$ and $m_{b}$ is the mass of particle $b$. The position vector from particle $b$ to particle $a$ is $\mathbf{r}_{a b}=\mathbf{r}_{a}-\mathbf{r}_{b}$ and the interpolation kernel with smoothing length $h$ evaluated at the distance $\left|\mathbf{r}_{a b}\right|$ is $W_{a b}=W\left(\mathbf{r}_{a b}, h\right)$. This form of the continuity equation has good numerical conservation properties and is not affected by free surfaces or density discontinuities.

\subsection{Momentum equation}

The momentum equation governing elastoplastic deformation of the solids is:

$\frac{\mathrm{d} \boldsymbol{v}^{\mathrm{i}}}{\mathrm{dt}}=\frac{1}{\rho_{\mathrm{s}}} \frac{\partial \boldsymbol{\sigma}^{\mathrm{ij}}}{\partial \mathrm{x}^{\mathrm{j}}}+\mathbf{g}^{\mathrm{i}}$

where $\boldsymbol{v}$ is velocity, $\mathbf{g}$ denotes the body force and $\boldsymbol{\sigma}$ is the stress tensor. Decomposing this into a pressure $P$ and a deviatoric stress $S$ gives:

$\sigma^{\mathrm{ij}}=-\mathrm{P} \delta^{\mathrm{ij}}+S^{\mathrm{ij}}$.

Using a linear elastic constitutive model with bulk modulus $K$ and shear modulus $G$, the evolution equation for the deviatoric stress from [17] is:

$\frac{d S^{i j}}{d t}=2 G\left(\dot{\varepsilon}^{i j}-\frac{1}{3} \delta^{i j} \dot{\varepsilon}^{k k}\right)+S^{i k} \Omega^{j k}+\Omega^{i k} S^{k j}$,

where the strain rates are given by:

$\dot{\varepsilon}^{i j}=\frac{1}{2}\left(\frac{\partial v^{i}}{\partial x^{j}}+\frac{\partial v^{j}}{\partial x^{i}}\right)$, 
and the Jaumann rotation tensor is:

$\Omega^{\mathrm{ij}}=\frac{1}{2}\left(\frac{\partial \mathrm{v}^{\mathrm{i}}}{\partial \mathrm{x}^{\mathrm{j}}}-\frac{\partial \mathrm{v}^{\mathrm{j}}}{\partial \mathrm{x}^{\mathrm{i}}}\right)$.

The SPH momentum equation is:

$\frac{\mathrm{d} \mathbf{v}_{\mathbf{a}}}{\mathrm{dt}}=\sum_{\mathrm{b}} \mathrm{m}_{\mathrm{b}}\left(\frac{\sigma_{\mathrm{a}}}{\rho_{\mathrm{a}}^{2}}+\frac{\sigma_{\mathrm{b}}}{\rho_{\mathrm{b}}^{2}}+\Pi_{\mathrm{ab}} \mathbf{I}\right) \cdot \nabla_{\mathrm{a}} \mathrm{W}_{\mathrm{ab}}+\mathbf{g}$,

where $\sigma_{\mathbf{a}}$ and $\sigma_{\mathbf{b}}$ are the stress tensors of particles $a$ and $b$, $\mathbf{g}$ is the gravity, and $\Pi_{a b}$ is an artificial viscosity originally formulated by [27]. For particle $a$, the SPH equations for calculating the strain rates and the rotation tensor $\Omega_{a}$ are:

$\dot{\varepsilon}_{\mathrm{a}}^{\mathrm{ij}}=\frac{1}{2} \sum_{\mathrm{b}} \frac{\mathrm{m}_{\mathrm{b}}}{\rho_{\mathrm{b}}}\left[\left(\mathrm{v}_{\mathrm{b}}^{\mathrm{i}}-\mathrm{v}_{\mathrm{a}}^{\mathrm{i}}\right) \frac{\partial \mathrm{W}_{\mathrm{ab}}}{\partial \mathrm{x}_{\mathrm{a}}^{\mathrm{j}}}+\left(\mathrm{v}_{\mathrm{b}}^{\mathrm{j}}-\mathrm{v}_{\mathrm{a}}^{\mathrm{j}}\right) \frac{\partial \mathrm{W}_{\mathrm{ab}}}{\partial \mathrm{x}_{\mathrm{a}}^{\mathrm{i}}}\right]$,

$\Omega_{\mathrm{a}}^{\mathrm{ij}}=\frac{1}{2} \sum_{\mathrm{b}} \frac{\mathrm{m}_{\mathrm{b}}}{\rho_{\mathrm{b}}}\left[\left(\mathrm{v}_{\mathrm{b}}^{\mathrm{i}}-\mathrm{v}_{\mathrm{a}}^{\mathrm{i}}\right) \frac{\partial \mathrm{W}_{\mathrm{ab}}}{\partial \mathrm{x}_{\mathrm{a}}^{\mathrm{j}}}-\left(\mathrm{v}_{\mathrm{b}}^{\mathrm{j}}-\mathrm{v}_{\mathrm{a}}^{\mathrm{j}}\right) \frac{\partial \mathrm{W}_{\mathrm{ab}}}{\partial \mathrm{x}_{\mathrm{a}}^{\mathrm{i}}}\right]$.

The Poisson ratio $\lambda$ is:

$\lambda=\frac{(3 K / G-2)}{2(3 K / G+2)}$.

\subsection{Equation of state}

The equation of state relating pressure $P$ and particle density is:

$P=c^{2}\left(\rho-\rho_{0}\right)$,

where $\rho_{0}$ is the reference density and the speed of sound is

$c=\sqrt{\frac{K}{\rho_{0}}}$.

Note that for modelling solid deformations the real speed of sound is used so that stress wave propagation is correctly resolved.

\subsection{Plasticity model}

Following [9] we use the radial return plasticity model of [33] for plastic deformation. A trial deviatoric stress $S_{T r}^{i j}$ is calculated assuming an initial elastic response giving an increment of plastic strain:

$\Delta \varepsilon^{p}=\frac{\sigma_{v m}-\sigma_{y}}{3 G+H}$,

where $\sigma_{v m}$ is the von Mises stress and $\sigma_{y}$ is the current yield stress. The plastic strain at the $i$ th time step is then given by:

$\varepsilon_{i}^{p}=\varepsilon_{i-1}^{p}+\Delta \varepsilon^{p}$.

At each time step the yield stress increment $\Delta \sigma_{y}$ is calculated:

$\Delta \sigma_{y}=H \Delta \varepsilon^{p}$, where $H$ is a hardening modulus. The deviatoric stress $S^{i j}$ at the end of a step is:

$S^{i j}=r_{s} S_{T r}^{i j}$,

where $r_{s}$ is the radial scale factor given by:

$r_{s}=\frac{\sigma_{y}}{\sigma_{v m}}$.

\subsection{Boundary conditions}

An important consideration is the boundary condition between the deforming solid and the rigid walls used for modelling the die. The boundary particles are included in both the SPH continuity and momentum equations summations (Eqs 1 and 7). This means that there is a shear force applied to the deforming solid at the rigid die wall and this is provided by the term $\Pi_{a b}$ which is viscous in nature. This interaction is simpler than the real boundary behaviour in that there is no frictional limit applied here. For many frictional materials there is a maximum shear force above which sliding occurs locally. Whilst simplified this is significantly better than assuming perfect slipping (which is not physical for such problems).

\subsection{Tensile instability correction}

The SPH method when used for quasi-compressible fluid flow $[10,28]$ exhibits noise in the form of fluctuations on the scale of the particles. This typically leads to particles jiggling and to large fluctuations in the pressure field which can lead to unphysical behaviour and numerical diffusion. This behaviour is usually attributed to the tensile instability that is inherent in classical (non-renormalised) formulations of SPH. For elastic or elastoplastic solids, there is a stronger requirement for stability under tension so a tensile stability correction is used. We use the approach proposed by [29] for fluid problems and then extended to elastic solid problems by [17]. This method involves explicitly removing a fraction of the tensile force in the principle frame of each particle to control the instability. It has been shown to be robust $[9,18,24]$ and it does not affect computational efficiency, unlike some of the alternative methods. The impact of this correction on the accuracy and stability of the classical SPH method for elastic deformation has recently been evaluated by [15]. The artificial viscosity $\Pi_{a b}$ in Eq. 7 is also chosen to damp unphysical fluctuations. The consequence of both these stabilisation measures is that particles should not exhibit unphysical fluctuations when solving solid deformation problems with SPH. 


\subsection{History dependent properties of the metal}

Each SPH particle represents a specific volume of material and carries information about that specific material with it. This is an important attribute of Lagrangian methods such as SPH. This means that information on the precise state of each elemental volume of metal can be known at all times and the history of each such volume is easily built into the particle data. This provides significant capability to track properties such as:

- Cumulative plastic strain

- Damage (which is a volume averaged local measure of cracking) leading to fracture prediction as shown in [14];

- Metal composition (including tracking multiple metals or metal composites) and trapped gas;

- Metallic phase and microstructure; and

- Surface oxide as demonstrated in [30] for aluminium ingot casting.

Some or all of these properties can then be used to feed back into the flow dynamics using suitable rheology models

\section{Parametric analysis for cold extrusion}

\subsection{Geometry and model setup}

Figure 1 shows a front view of the geometry used for the parametric study. It consists of a cylindrical billet of diameter $D=40 \mathrm{~mm}$ which is cold extruded by a punch moving at a constant speed of $25 \mathrm{~m} / \mathrm{min}$ through a die with exit diameter $d$. We consider three diameters of 20,15 or $10 \mathrm{~mm}$ with extrusion ratios, defined as $\left(\frac{D}{d}\right)^{2}$, of 4.0, 7.1 and 16.0. Die angles of $\theta=120,140$ or 160 degrees were also considered. The material used is a generic aluminium alloy with properties given in Table 1. Although strain hardening is included in the plasticity model we do not use any here in order to simplify the subsequent analysis. The effect of hardening will be examined in future work. The modelling is performed in three dimensions so as not to artificially enforce any symmetry on the material flow. An SPH particle resolution of $1.6 \mathrm{~mm}$ was used giving a total of 7,760 particles for these simulations.

\subsection{Basic extrusion flow pattern}

Figure 2 shows the metal flow pattern as the billet is extruded through the circular die with a diameter of $20 \mathrm{~mm}$ and angle of $120^{\circ}$. The metal is shaded by its flow velocity with a maximum value of $2.0 \mathrm{~m} / \mathrm{s}$ (shown as red) and zero velocity being blue. Such extrusion processes have three phases:

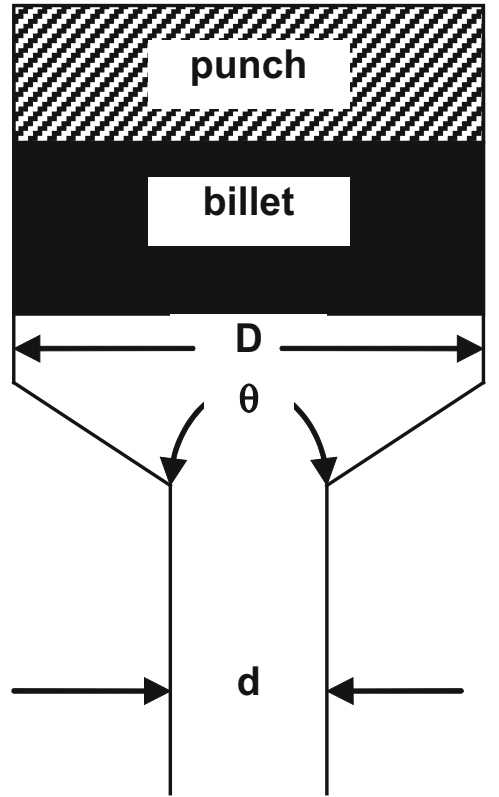

Fig. 1 Schematic diagram of the simple cylindrical extrusion configuration

Table 1 Properties of $\mathrm{Al}$ alloy used for cold extrusion

\begin{tabular}{lc}
\hline Bulk modulus $(\mathrm{GPa})$ & 7.0 \\
Shear modulus $(\mathrm{GPa})$ & 2.70 \\
Initial yield stress $(\mathrm{MPa})$ & 5.52 \\
Hardening modulus $(\mathrm{MPa})$ & 0.0 \\
Density $\left(\mathrm{kg} / \mathrm{m}^{3}\right)$ & 2700.0 \\
\hline
\end{tabular}

1. Phase 1 where the punch pushes the billet into the tapered section of the die when the extrusion force ramps up steeply.

2. Phase 2 where the metal is pushed through the die exit and is extruded as the product. This phase requires a constant extrusion force.

3. Phase 3 where the rear of the billet approaches the convergent die section. In this phase the extrusion force drops off.

At $10 \mathrm{~ms}$, the punch (not shown in the figure) has begun pushing the billet into the tapered section of the die. At $20 \mathrm{~ms}$, the metal has almost completely filled the tapered section. This concludes phase 1 of the extrusion process. The leading edge of the metal has accelerated to around $0.5 \mathrm{~m} / \mathrm{s}$, which is close to the pushing speed of the punch. At $30 \mathrm{~ms}$, approximately a quarter of the metal has been extruded through the die. As the metal is forced through the die exit its velocity accelerates to around $1.5 \mathrm{~m} / \mathrm{s}$. Distinct high velocity extruded and low velocity non-extruded regions in the billet can be seen. At $40 \mathrm{~ms}$, around half the metal has been extruded through the die with a uniform high velocity of around $1.8 \mathrm{~m} / \mathrm{s}$. This 
Fig. 2 Metal flow pattern as it is extruded through die with circular cross-section. The metal is shaded by velocity with blue being zero and red a maximum of $2.0 \mathrm{~m} / \mathrm{s}$. (Colour figure online)
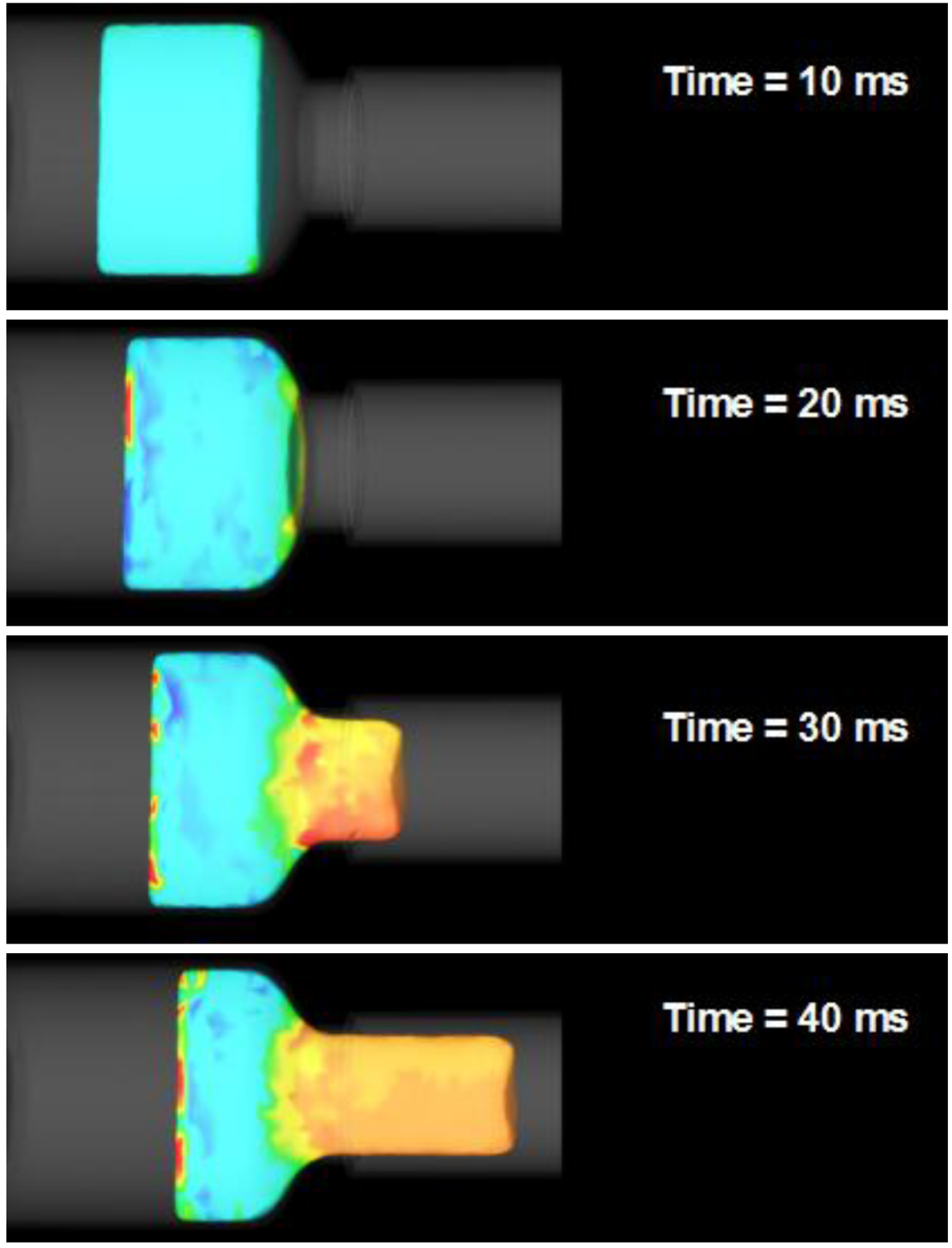

Time $=70 \mathrm{~ms}$

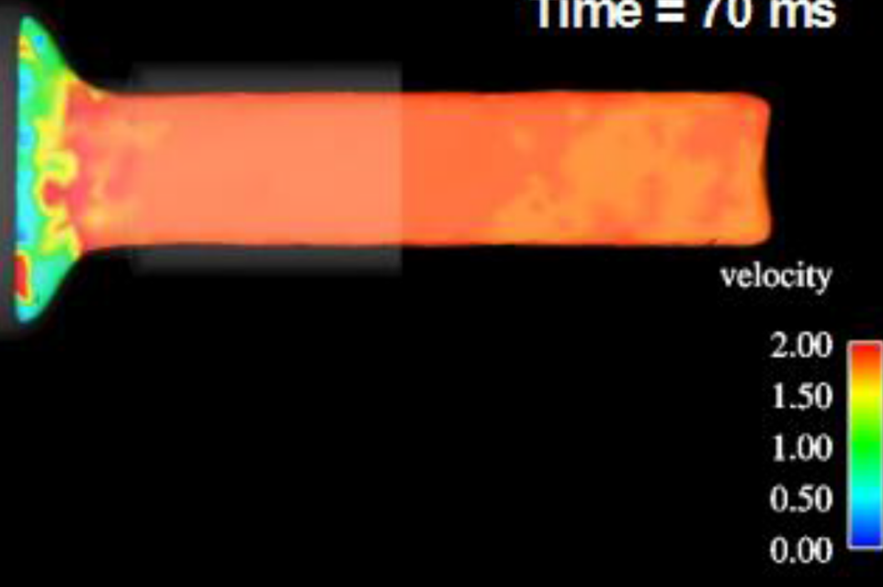


Fig. 3 Change in metal deformation with die diameter; (a) $20 \mathrm{~mm},(b) 15 \mathrm{~mm}$, and (c) $10 \mathrm{~mm}$. The metal is initially coloured by four equal volume horizontal strata. The die is sectioned at its mid-plane so that the internal structure of the extrusion is visible
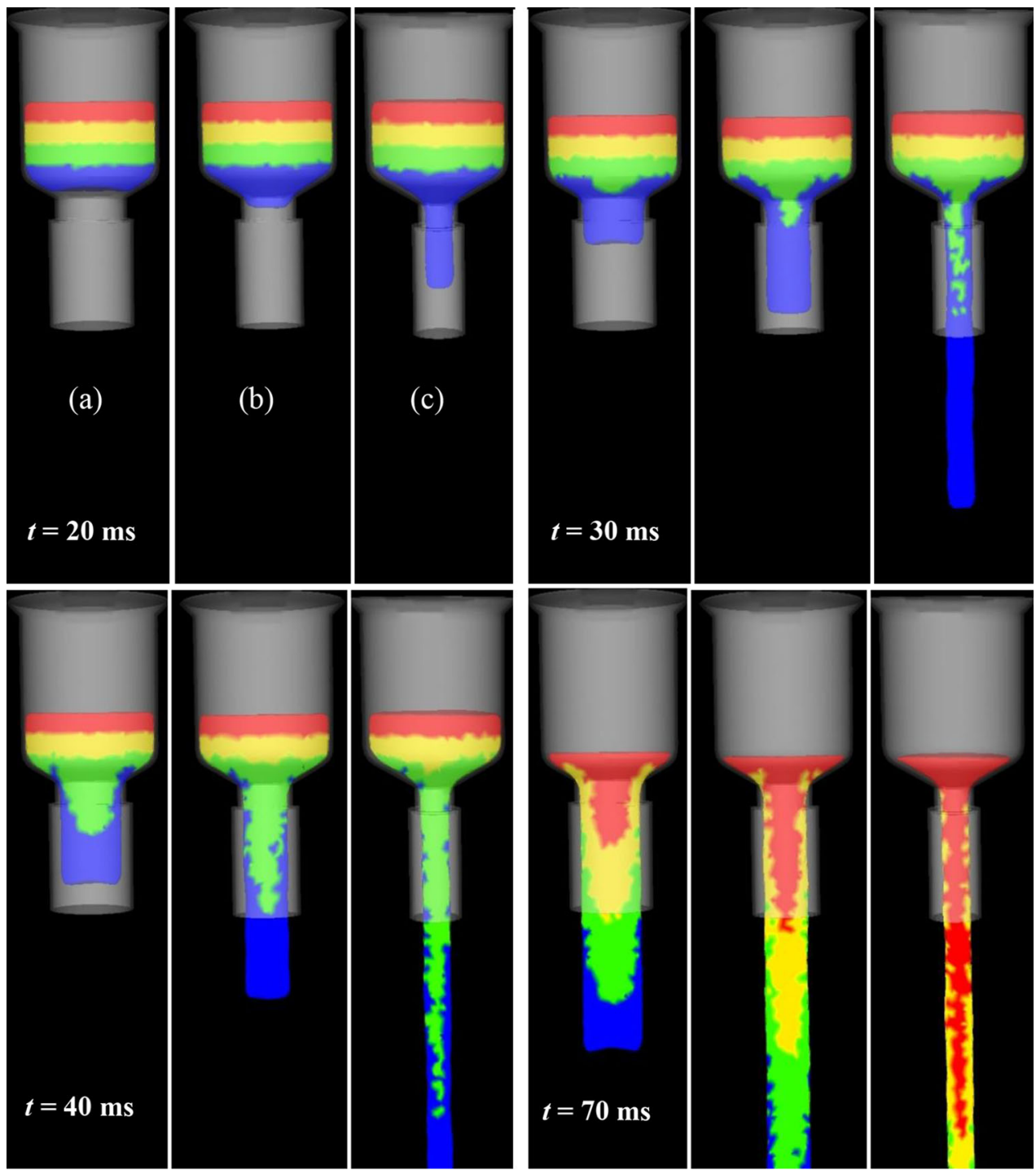

is phase 2 of the extrusion process. By $70 \mathrm{~ms}$, almost the entire billet has been extruded with only a small portion filling the tapered section of the die. The rear of the billet starts approaching the convergent section of the die which is the start of Phase 3.

The metal flow and deformation through the tapered section of the die into its exit as the extruded product was easily modelled by the SPH method. The solution process was stable for all extrusion ratios and die angles. The variation in metal velocity from 2.0 to $7.5 \mathrm{~m} / \mathrm{s}$ and the high levels of plastic strain also did not affect the stability of the numerical solution.

\subsection{Effect of die diameter on deformation, plastic strain and extrusion force}

The effect of die orifice diameter on internal billet deformation and plastic strain is evaluated using three cases with die exit diameters of 20,15 and $10 \mathrm{~mm}$, which correspond to extrusion ratios of 4.0, 7.1 and 16.0. The die angle for these three cases is fixed at $120^{\circ}$. Figure 3 shows metal deformation profiles on cross-sections through the mid-plane of the billet for the three exit diameters. The billet is coloured in four horizontal strata based on initial material position so we can track the internal metal deformation profile.

At $20 \mathrm{~ms}$, the metal has just started moving into the tapered section of the die for the $d=20 \mathrm{~mm}$ case, has just filled the tapered section for $d=15 \mathrm{~mm}$ and is already being extruded for $d=10 \mathrm{~mm}$. At $30 \mathrm{~ms}$, the first layer of metal has begun pushing through the die for $d=20 \mathrm{~mm}$. For the two smaller diameters this layer has already been substantially extruded. Metal in the central part of the converging region moves faster than metal near the angled sides of the die. This is a boundary layer type of effect which means that material towards the side of the billet is extruded much more gradually than material closer to the centre of the billet. This effect is more pronounced for the smaller diameters due to the large extrude ratio. Subsequent layers are extruded in a similar 
manner. The slow moving material near the sides of the die results in a stagnation zone at the circumference of the die exit.

At $40 \mathrm{~ms}$, metal from the first layer has almost completely extruded through the die for $d=20 \mathrm{~mm}$ with the second layer starting to push through the die entrance. For $d=15 \mathrm{~mm}$, a majority of the first layer has moved well past the die exit with a thin section left behind close to the side walls. For $d=10 \mathrm{~mm}$, mixing between the green and blue colours is seen closer to the leading edge of the extruded product. For the smaller diameters there is also an increase in the elongation of the layers as they pass through the die. For the smallest die, the centre of the third (yellow) band is just starting to move ahead of the rest of the bands indicating that this band has just reached the converging region of the flow. The interface of the second to third colour band remains close planar for the two larger dies indicating that the billet is moving almost as a rigid body at this point without much internal flow and deformation. The interface between the last two colour bands is completely planar for all three cases indicating that there is no flow or deformation at this distance from the orifice.

At $70 \mathrm{~ms}$, the metal has almost completely extruded through the die for all three cases. For $d=20 \mathrm{~mm}$, the strata interfaces have significantly deformed with essentially parabolic shapes as the metal is extruded through the die. The interface between the colour bands is sharp but uneven due to mixing between the layers. At $70 \mathrm{~ms}$ the maximum elongation of the coloured strata is twice the diameter for $d=20 \mathrm{~mm}, 4$ times for $d=15 \mathrm{~mm}$ and as much as 10 times the diameter for $d=10 \mathrm{~mm}$. The advection of the material colours shown here is a simple example of the history tracking ability of the SPH method. This is relevant especially in instances where multiple materials are extruded and their relative positions in the extruded product are critical for product quality and material strength. Achieving this with the same level of stability and accuracy as SPH with a mesh based method would require the solution of an advection equation with a higher order scheme combined with explicit interface tracking techniques to prevent numerical diffusion.

The degree of metal deformation increases significantly with an increase in the extrusion ratio. The elongation of the layers as the metal is deformed can have important implications for the final product microstructure. For example it has been shown experimentally by [5] that for large extrusion ratios $(>7)$ there is a significant increase in grain refinement and elongation for $\mathrm{Mg}$ alloy. The SPH method allows the simulation of such large extrude ratios without the need for frequent complex re-meshing.

Figure 4 shows the same cases but now coloured by corresponding percentage plastic strain with blue being zero and red showing a maximum strain level fixed at $400 \%$. At $20 \mathrm{~ms}$, for $d=20 \mathrm{~mm}$ the plastic strain levels are still very low. For $d=15 \mathrm{~mm}$, the metal has moved into the die exit with about a quarter of the billet experiencing moderate amounts of strains of around $150 \%$. Once the corners of the billet contact the converging walls of the die, the metal is quickly loaded elastically and then begins undergoing plastic deformation. For $d=10 \mathrm{~mm}$, a reasonable amount of metal has already been extruded through the die with the metal experiencing high strain levels in excess of $300 \%$ as it passes through the relatively small die orifice. At $30 \mathrm{~ms}$, for the $d=20 \mathrm{~mm}$ case the extruded section has moderate strain levels of up to $150 \%$ symmetrically distributed about the centre of the die. A low strain region exists at the leading edge of the metal. Since the extrusion ratio for $d=15 \mathrm{~mm}$ is larger the plastic strain is correspondingly larger and around $250 \%$ close to the die orifice. The material at the leading edge has lower strain levels of around $150 \%$ compared to the bulk of the extruded product. For $d=10 \mathrm{~mm}$, very large strain levels of between 350 and $400 \%$ are experienced by all the extruded metal except in a region close to the leading edge which has a lower strain of around $200 \%$ (green to blue coloured metal). The high strain levels observed for the larger extrude ratios can lead to grain refinement which in turn would increase the material strength.

By $40 \mathrm{~ms}$, for $d=20 \mathrm{~mm}$, the central region except at the leading edge has strains of around $160 \%$ with peak strains at the outer surface reaching $200 \%$. For $d=15 \mathrm{~mm}$, medium strain levels of $200 \%$ are now seen even in the central region of the extruded product. These medium strains are developed since the two high plastic strain regions from the sides of the cylindrical die do not meet and could lead to a defect referred to as chevron crack (see descriptions in [21] and [31]). The occurrence of this central medium strain zone can be reduced by increasing the extrusion ratio as seen from the $d=10 \mathrm{~mm}$ case. By $70 \mathrm{~ms}$, the central medium strain zone is clearly seen for the $d=20 \mathrm{~mm}$ case as the billet is almost fully extruded through the die. The central section coloured light blue has strain levels of around $160 \%$ whereas the outer region has higher strain levels of $200 \%$. As the end of the billet approaches the convergent section a clear strain concentration occurs in the central core. For $d=15 \mathrm{~mm}$, the central medium strain regions are more stretched and less pronounced. High strain level of $400 \%$ can be seen in the convergent section at the central core at the end of the billet. This localised strain can lead to the extruded product cracking at this point resulting in reduced product length. For $d=10 \mathrm{~mm}$, the metal passes through the die with high strain levels of between 350 to $400 \%$ throughout the metal mass. A uniformly high level of strain is good for the product since it can lead to improved grain refinement. For large extrude ratios, high levels of plastic strain in the extruded product is an indication of high levels of metal elongation as seen in the previous section. The simulations show that even at very 
Fig. 4 Change in plastic strain with die diameter $(a) 20 \mathrm{~mm},(b)$ $15 \mathrm{~mm}$, and $(c) 10 \mathrm{~mm}$. The metal is coloured by plastic strain with blue being zero and red indicating a strain of $400 \%$. The die is sectioned at its mid-plane so that the internal structure of the extrusion is visible. (Colour figure online)
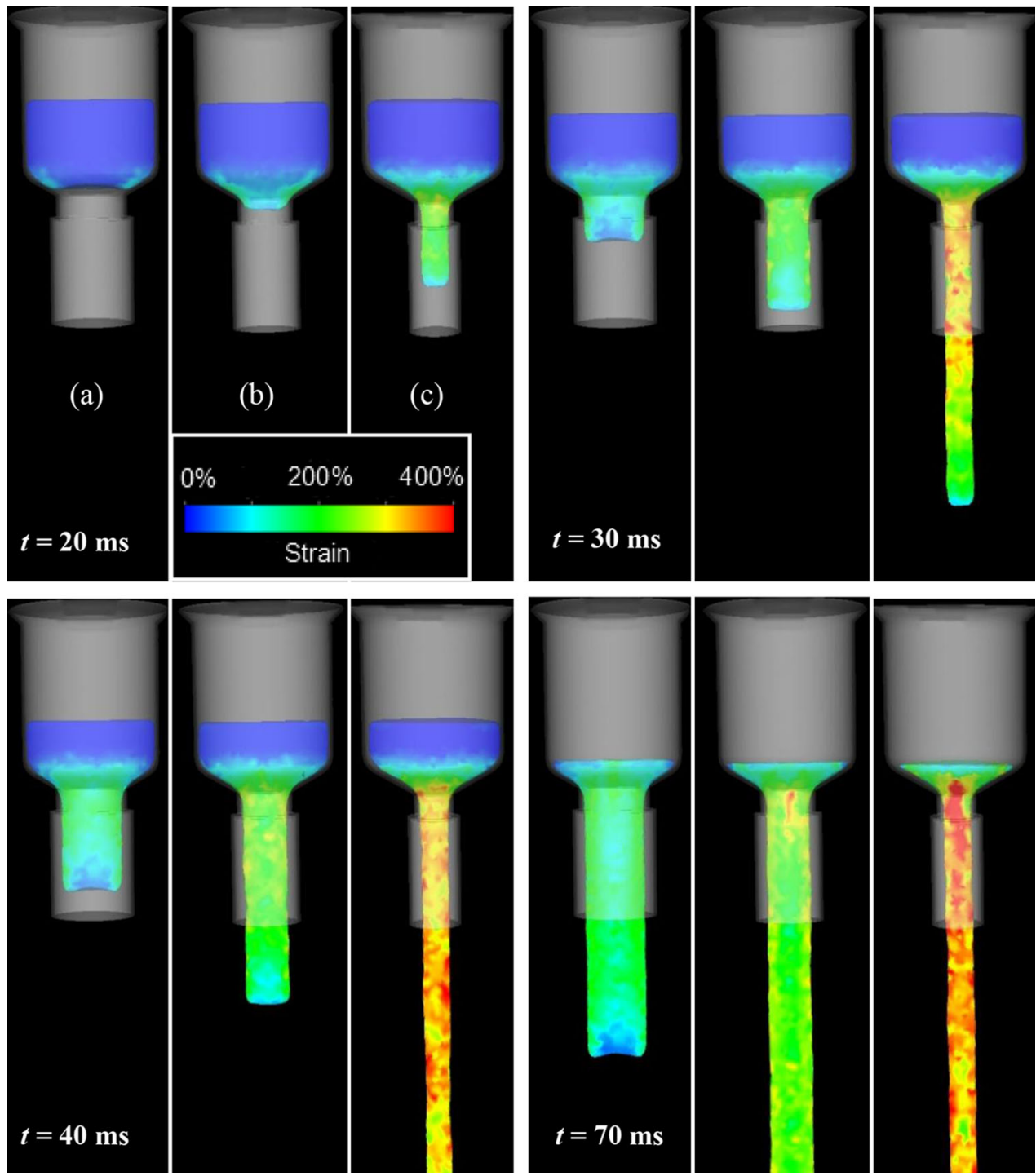

high extrusion ratios leading to large deformations no special treatment is required with the SPH methodology.

Figure 5 compares the radial distribution of plastic strain at $70 \mathrm{~ms}$ in the extruded product for the three die orifices. For $d=20 \mathrm{~mm}$, there is a wide distribution in the strain level experienced by the extruded metal ranging from 40 to $230 \%$. The strain distribution is broader closer to the centre than the surface of the extruded product. For regions close to the surface the strain distribution lies in a tighter band between 80 and $200 \%$ with only a few particles experiencing strain levels outside this range. The lower level of strain in the centre of the extruded product compared to the surface could lead to chevron crack defects due to the presence of two independent plastic strain zones. For $d=15 \mathrm{~mm}$, there is a moderate increase in the overall level of plastic strain experienced by the extruded metal. For approximately $90 \%$ of the metal, the strain lies in a range between 120 and $300 \%$. Near the surface, the strain lies in a narrower high range of $170-300 \%$. The difference in the strain distribution between the centre and the surface is approximately $14 \%$ less than for $d=20 \mathrm{~mm}$. For $d=10 \mathrm{~mm}$, around $90 \%$ of the metal experiences strain in the region of 250 to $400 \%$. The radial strain distribution is the same in the centre and the surface of the extruded metal. This demonstrates that at high extrude ratios the central low strain zone leading to chevron cracks is absent.

Extrusion force is the force with which the punch needs to be pushed to extrude the metal through the die orifice. Figure 6 shows the effect of die diameter on the extrusion force. Here it can be seen that in phase 1 of the extrusion process, the force ramps up over the first 15-20 ms to a maximum value as the billet fills the converging region around the die inlet. This is fastest and leads to the highest force for the smallest $d=10 \mathrm{~mm}$ orifice and slowest and lowest force for the largest orifice. Between 20 and $60 \mathrm{~ms}$, in phase 2, the metal is extruded at a nearly constant rate through the die with the force being consistently around its maximum level but with small fluctuations around these levels. The aver- 



Fig. 5 Radial variation in plastic strain for die orifice diameters of a $20 \mathrm{~mm} \mathrm{~b} 15 \mathrm{~mm}$, and $\mathbf{c} 10 \mathrm{~mm}$ at $70 \mathrm{~ms}$

age extrusion force experienced during this steady middle phase is $12 \mathrm{kN}$ for $d=20 \mathrm{~mm}, 17 \mathrm{kN}$ for $d=15 \mathrm{~mm}$ and $30 \mathrm{kN}$ for $d=10 \mathrm{~mm}$. So there is a clear increase in the average extrusion force with the decreasing die orifice diameter. The amplitude and irregularity of the fluctuations also increase with decreasing orifice diameter. These oscillations could lead to chatter cracks as defined in [20], which are surface defects at right angles to the direction of extrusion, in the extruded metal. One means of reducing these cracks is by reducing the extrusion speed but this leads to reduced productivity.

During phase 3 , as the rear of the billet approaches the converging region of the die, the extrusion force declines rapidly. This decline is almost linear for the largest die diameter. For

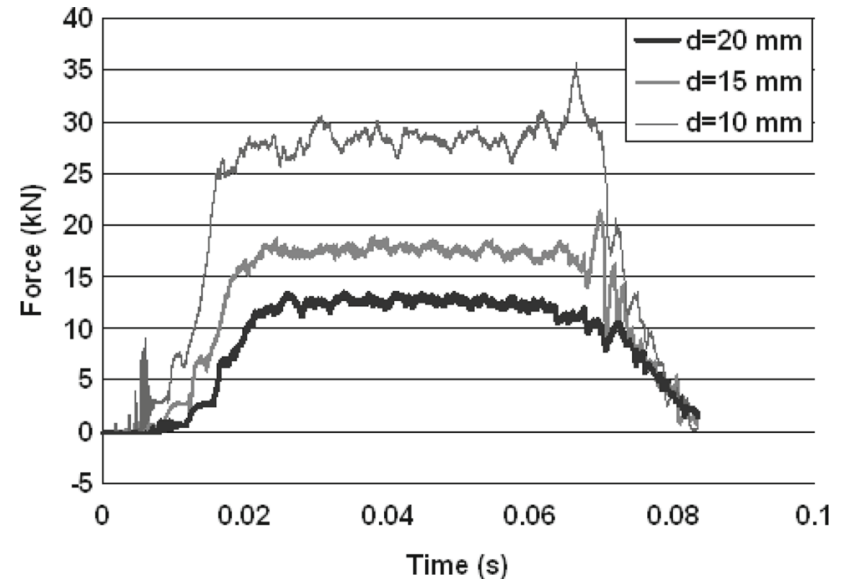

Fig. 6 Force on piston during extrusion as a function of time for three die orifice diameters

Table 2 Variation of average extrusion force with die diameter and angle, during steady operation

\begin{tabular}{lllll}
\hline Case & $\begin{array}{l}\text { Die exit } \\
\text { diameter } \\
(\mathrm{mm})\end{array}$ & $\begin{array}{l}\text { Die angle } \\
\text { (degrees) }\end{array}$ & $\begin{array}{l}\text { Extrusion } \\
\text { ratio }\end{array}$ & $\begin{array}{l}\text { Maximum } \\
\text { force }(\mathrm{kN})\end{array}$ \\
\hline 1 & 20 & 120 & 4.0 & 12 \\
2 & 15 & 120 & 7.1 & 17 \\
3 & 10 & 120 & 16.0 & 30 \\
4 & 20 & 140 & 4.0 & 13 \\
5 & 20 & 160 & 4.0 & 14 \\
\hline
\end{tabular}

the smaller diameters, there is a large single oscillation followed by a sharp drop in force followed by a linear decline. As shown in Table 2, the maximum extrusion force for the main second phase increases with increasing extrusion ratio. The $d=10 \mathrm{~mm}$ case experiences the largest phase 2 force of $30 \mathrm{kN}$ which is around 1.7 times greater than the $d=15 \mathrm{~mm}$ case and 2.5 times greater than $d=20 \mathrm{~mm}$.

A reduction in the die exit diameter therefore has the effect of increasing elongation of the metal layers leading to grain refinement, as reported in [6]. If the billet is made of recycled material containing oxide, then the deformation can lead to more uniform contaminant dispersion throughout the extruded part resulting in higher material strength and fatigue resistance due to higher tensile strength and yield stress. Such increased material strength is, however, achieved at the cost of an increase in the extrusion force as seen from Table 2. The higher extrusion force results in an increased power requirement to push the punch.

\subsection{Effect of die angle on deformation, plastic strain and extrusion force}

The effect of die angle on internal billet deformation and plastic strain is evaluated using three die angles of 120,140 
Fig. 7 Variation in metal deformation with die angle; $(a)$ $120^{\circ}$, (b) $140^{\circ}$, and (c) $160^{\circ}$. The metal is coloured as four initially equal volume horizontal strata. The die is sectioned at its mid-plane so that the internal structure of the extrusion is visible
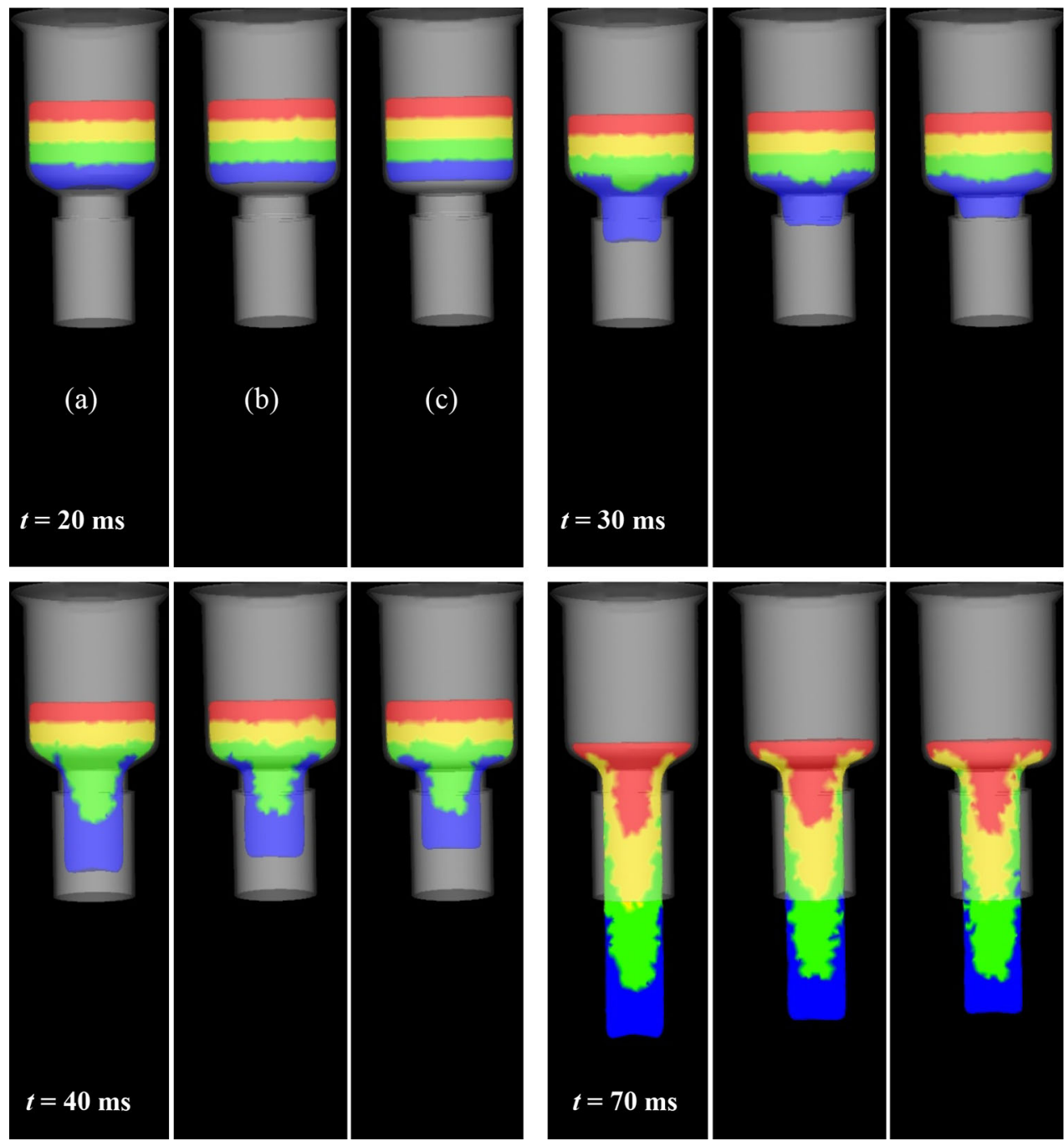

and $160^{\circ}$ for the die geometry shown in Fig. 1. Figure 7 shows metal deformation profiles on a cross-section through the mid-plane of the billet for the three die angles. The billet here is coloured in four horizontal strata based on initial material position in order to track the deformation. Overall the metal deformation profile is similar for all three cases. The interface between the colours is initially horizontal but becomes broadly parabolic as the metal is extruded through the die. There is very little change in the shape of the interface profiles with die angle.

The metal starts flowing through the die exit first for a die angle of $120^{\circ}$ at $30 \mathrm{~ms}$ since the convergent section in phase 1 extrusion is least for the smallest die angle. With an increase in die angle from 120 to $160^{\circ}$ the size of the region to be filled in phase 1 increases by approximately $10 \%$. At $40 \mathrm{~ms}$, for higher die angles the sides of the stratum coloured blue is retarded and is extruded with the stratum coloured green behind it. This retardation of the metal flow is further seen at $70 \mathrm{~ms}$ where the edge of the stratum coloured yellow is extruded with the last stratum coloured red. This lag in the extrusion of metal from the edge can distort the material leading to product warpage, a defect commonly seen due to the use of large die angles as illustrated experimentally in [23].

The elongation of each stratum for the final extruded product shows that the first blue layer has the smallest elongation. There is little variation in the elongation for this layer for die angles of 120 and $140^{\circ}$ and is around twice the product diameter. The elongation increases marginally to about 2.2 times the product diameter for the $160^{\circ}$ die angle. For the second green stratum, which is the only other layer completely extruded, there is a significant increase in the elongation especially for the larger die angles. For $120^{\circ}$ angle the elongation is 2.2 times the product diameter. This increases to almost 3.0 times the product diameter for $140^{\circ}$ and further to around 3.8 times the product diameter for $160^{\circ}$. The increase in the elongation suggests greater levels of plastic strain for the larger die angle. Lower elongation for the first stratum suggests that the plastic strain will be lower at the leading edge of the product.

Figure 8 shows the billet coloured by the magnitude of the plastic strain, with blue being zero and red showing the 
Fig. 8 Variation in plastic strain with die angle; (a) $120^{\circ}$, (b) $140^{\circ}$, and (c) $160^{\circ}$. The metal is coloured by plastic strain with blue being zero and red indicating a strain of $210 \%$. The die is sectioned at its mid-plane so that the internal structure of the extrusion is visible. (Colour figure online)

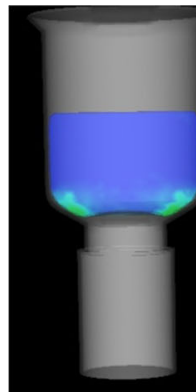

(a)

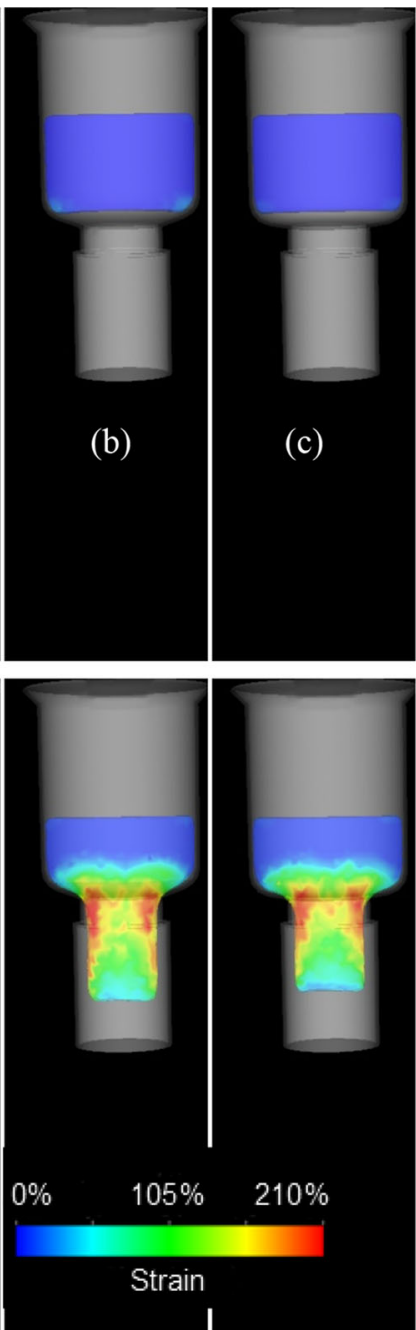


maximum strain of $210 \%$. At $20 \mathrm{~ms}$, the metal at the leading edge has begun plastically deforming to match the shape of the die entrance. Modest plastic strains of $80 \%$ (light blue) are observed. For the larger die angles the metal front is still flat and the billet has not yet loaded sufficiently to start deforming plastically. At $30 \mathrm{~ms}$, for $120^{\circ}$ the metal close to the die orifice has strain levels close to $210 \%$ whereas the leading edge has a low strain level of less than $60 \%$. At $40 \mathrm{~ms}$, first phase of the extrusion process has ended for all three die angles. The metal flow is now fully developed and end effects are no longer influencing the strain distribution of the extruded metal. Higher strain levels are seen at the circumference of the extruded metal as it flows through the convergent conical region of the die. This strain concentration increases with die angle. The increased strain results in increased metal elongation with die angle. The distribution of strain in the core is similar for all three die angles. At the leading edge of the extruded product a $\mathrm{V}$-shaped low plastic strain region is formed for all three cases. For all three die angles there is a central low to medium plastic strain zone in the extruded product which could lead to the development of chevron cracks.

Figure 9 compares the radial variation in plastic strain for the three different die angles. With increasing die angle the spread of plastic strain experienced becomes wider. For $120^{\circ}$ the range is from 50 to $220 \%$ whereas for $160^{\circ}$ the range is $30-260 \%$. The inhomogeneity in plastic strain increases with increasing die angle which could lead to higher annealing times post extrusion. The use of lower die angles for the same extrusion ratio would seem to be advantageous for product quality. The central low strain zone exists for all three die angles demonstrating that the chevron crack defect could occur for all three cases and is predominantly a function of the extrusion ratio.

Figure 10 shows the effect of die angle on the extrusion force. There is an increasing delay in the commencement of extrusion with die angle because the metal is filling the region around the die exit during phase 1 . This region has a higher volume for larger die angles. Phase 2 occurs between 20 and $60 \mathrm{~ms}$. During this period of steady operation the extrusion 

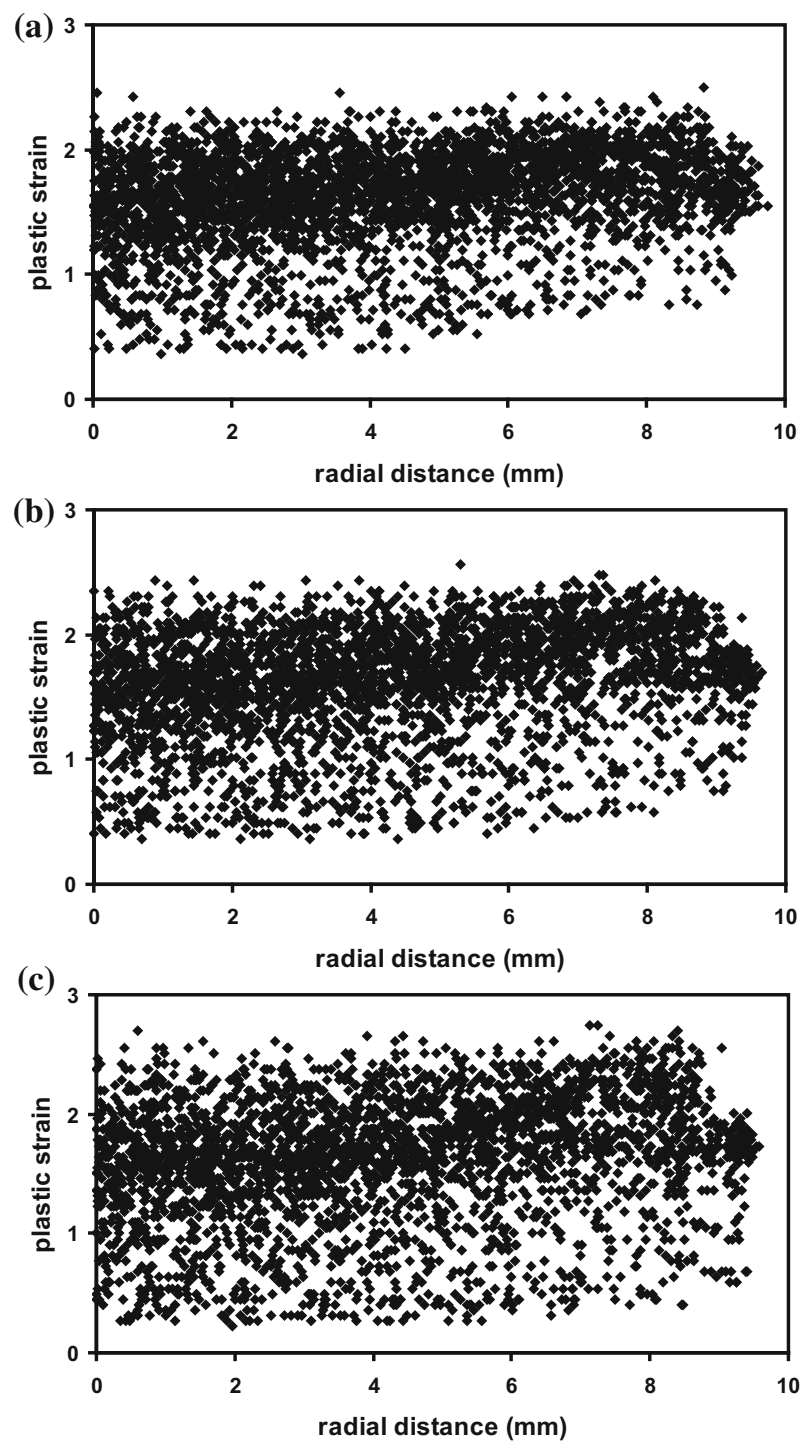

Fig. 9 Radial variation in plastic strain for die angles of $\mathbf{a} 120^{\circ} \mathbf{b} 140^{\circ}$ and $\mathbf{c} 160^{\circ}$ at $70 \mathrm{~ms}$

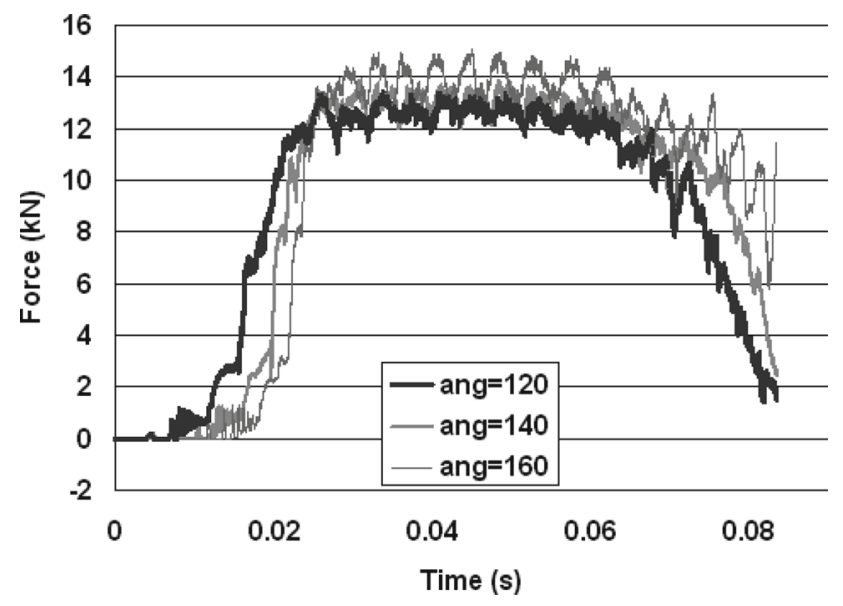

Fig. 10 Extrusion force as a function of time for three die angles force is relatively constant with moderate oscillations. The average extrusion force (summarised in Table 2) is $12 \mathrm{kN}$ for $120^{\circ}, 13 \mathrm{kN}$ for $140^{\circ}$ and $14 \mathrm{kN}$ for $160^{\circ}$ which represents a weak linear increase with increasing die angle. The force oscillations arise from stick-slip like behaviour where the billet shows intermittent motion due to high extrusion speed and lack of lubrication. This behaviour is likely to also be dependent on the form of the metal-die shear boundary condition. In this case, a simple viscous interaction is used without a sliding frictional limit. It is interesting that even such a simple boundary condition enables development of this for of behaviour. The oscillation amplitude in the force increases almost linearly with die angle and are 1.2, 1.8 and $2.4 \mathrm{kN}$ respectively. The frequency of this oscillation remains almost the same for all three die angles and lies in the range of $115-130 \mathrm{~Hz}$.

\section{Extrusion modelling of complex cross-section}

\subsection{Geometry and model setup}

A metallic component used in the building industry is simulated to demonstrate the ability of SPH to handle extrusion of complex shaped parts in three dimensions. Figure 11 shows the cross-section and setup used for simulating the extrusion of this component. The central part of the die is disc shaped with four symmetrically placed rectangular ribs. The external cross-section is square with chamfered corners and a side length of $100 \mathrm{~mm}$. Four symmetrically placed flanges attached to the square cross-section protrude into the central part of the die. The large gap between the central and external part contains four symmetric eye-shaped features. The width of the thinnest section of the component is $5 \mathrm{~mm}$. The length of the metal billet is $150 \mathrm{~mm}$. A square piston is used to push the rectangular billet through the die at a speed of $25 \mathrm{~m} / \mathrm{min}$. Metal flows into the gap between the external and central section of the die creating a complex structure. The SPH particle size used in this case was $2 \mathrm{~mm}$ leading to approximately 190,000 metal SPH particles for this 3D simulation. The alloy properties are the same as for the previous cases and are given in Table 1.

\subsection{Metal flow pattern}

Figure 12 shows the metal flow pattern as the billet is extruded through this complex die. Frames on the left show the metal surface and frames on the right show a longitudinal crosssection of the metal so that the internal structure of the extrusion can be examined. The metal is shaded by velocity with blue indicating zero and red indicating a maximum velocity fixed at $2.0 \mathrm{~m} / \mathrm{s}$. Initially, the metal billet is stationary and so all the metal particles are shaded blue. At $20 \mathrm{~ms}$, 


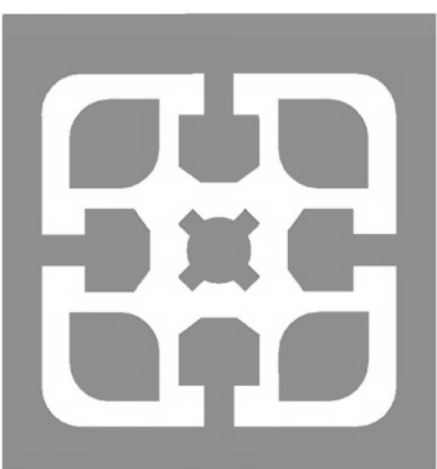

(a)



(b)

Fig. 11 Cold extrusion of complex building component, a die cross-section, and $\mathbf{b}$ simulation configuration

metal contacts the front walls of the die as it is pushed by the punch into the complex die cross-section. This results in localized high velocity regions on the surface of the billet. These can be attributed to stick-slip motion where the billet moves intermittently rather than continuously. According to [22] stick-slip occurs if there is lack of lubrication and if the punch speed is high resulting in oscillations in various quantities including local velocity and extrusion force. The stick-slip motion can result in undesirable surface markings on the extruded product.

At $50 \mathrm{~ms}$, approximately $10 \%$ of the metal has extruded through the die. The extruded section has a uniform high velocity of $1.5 \mathrm{~m} / \mathrm{s}$. By $120 \mathrm{~ms}$, approximately $40 \%$ of the metal has extruded through the die. The metal flow pattern remains fairly steady with distinct and uniform high velocity extruded and low velocity non-extruded regions. This results in a high velocity gradient in the metal in the transition zone just before the orifice that could cause high strain levels. By $269 \mathrm{~ms}$, around $90 \%$ of the metal has extruded through the die. The length of the extruded metal is approximately $250 \mathrm{~mm}$ compared to an initial billet length of $150 \mathrm{~mm}$. Three distinct flow phases can be seen in the extrusion of the billet here:

- In phase 1 , the material between the punch and die behaves as a uniformly moving rigid body.

- In phase 2, the region around the die exit has the metal experiencing high levels of plastic strain. The metal accelerates significantly as it converges towards the die orifice resulting in high velocity. The area ratio between the billet and the die orifice is 2.3:1. Flow separation of the metal occurs around the die exit with stagnation due to the large die angle. The region shows similar flow behaviour to the large die angle case seen for the simpler geometry.

- In phase 3, the extruded metal leaving the die moves with a uniform high velocity.

\subsection{Variation in plastic strain}

Figure 13 shows the progress of the extrusion where the metal is coloured by plastic strain. The metal with zero strain is coloured blue and red shows strain levels of $300 \%$. Frames on the left show the surface of the billet and frames on the right show a cross-section at the centre. The punch pushes the metal towards the die exit and at $20 \mathrm{~ms}$ the leading edge of the billet contacts the walls of the die cross-section. Metal close to the die exit is elastically loaded and begins to deform plastically.

At $50 \mathrm{~ms}$, convergence of the metal on approach to the orifice into the die leads to pressure build up resulting in strong plastic strain due to the $180^{\circ}$ die angle. Metal around the die exit experiences increasing amounts of plastic strain reaching values of around $160 \%$. The cut section shows that strain levels of more than $160 \%$ are also experienced by the metal where it is in contact with the internal die structure.

At $120 \mathrm{~ms}$, plastic strain close to the die exit has increased significantly with maximum values reaching around $300 \%$. Regions of high plastic strain are now seen in the extruded product surface except at the leading edge. High strain regions are also seen in the internal cut-section of the metal in the extruded product. The strain inside the billet remains low on approach to the die opening until extremely close to the orifice. At $120 \mathrm{~ms}, 80 \mathrm{~mm}$ of metal has been extruded through the die. This indicates that the deformation of the metal at the opening is confined to a very thin region just 
Fig. 12 Metal flow pattern for cold extrusion through a complex die. The metal is shaded by velocity with blue being zero and red a maximum of $2.0 \mathrm{~m} / \mathrm{s}$. (Colour figure online)



before the orifice and to the surface of the die closer to the punch.

At $269 \mathrm{~ms}$, the plastic strain of the material varies significantly across the length of the extruded product on two scales. The first is a variation along the length of the billet and related to the material moving as a uniform rigid body in phase 1 of the extrusion process. This causes high strain levels of around $300 \%$ for the first $60 \%$ of the metal closer to the die orifice on the surface. The strain levels then drop off abruptly closer to the leading edge of the extruded product. There is also a mottled fine scale variation of the strain mainly visible in the internal cut-section of the metal but also on the surface that has a more uniform distribution. This second level strain variation is only seen in the extruded product and is caused by the interaction of the metal with the die exit with a large die angle of $180^{\circ}$ during phase 2 extrusion.

In order to explore the nature of the spatial variation of the plastic strain, we plot the strain distribution across the length of the extruded product for different times in Fig. 14. The origin of the extrusion distance is at the die exit with positive being outside the die. At $50 \mathrm{~ms}$ when $25 \mathrm{~mm}$ of the extruded product is formed, the maximum strain level along the product length is uniform for the first $15 \mathrm{~mm}$. The maximum strain level at this time is $40 \%$. The maximum plastic 
Fig. 13 Extrusion through a complex die with metal shaded by plastic strain. Blue is zero and red indicates strain level of $300 \%$. Frames on the right are a section cut across the mid-plane of the extruded metal. (Colour figure online)
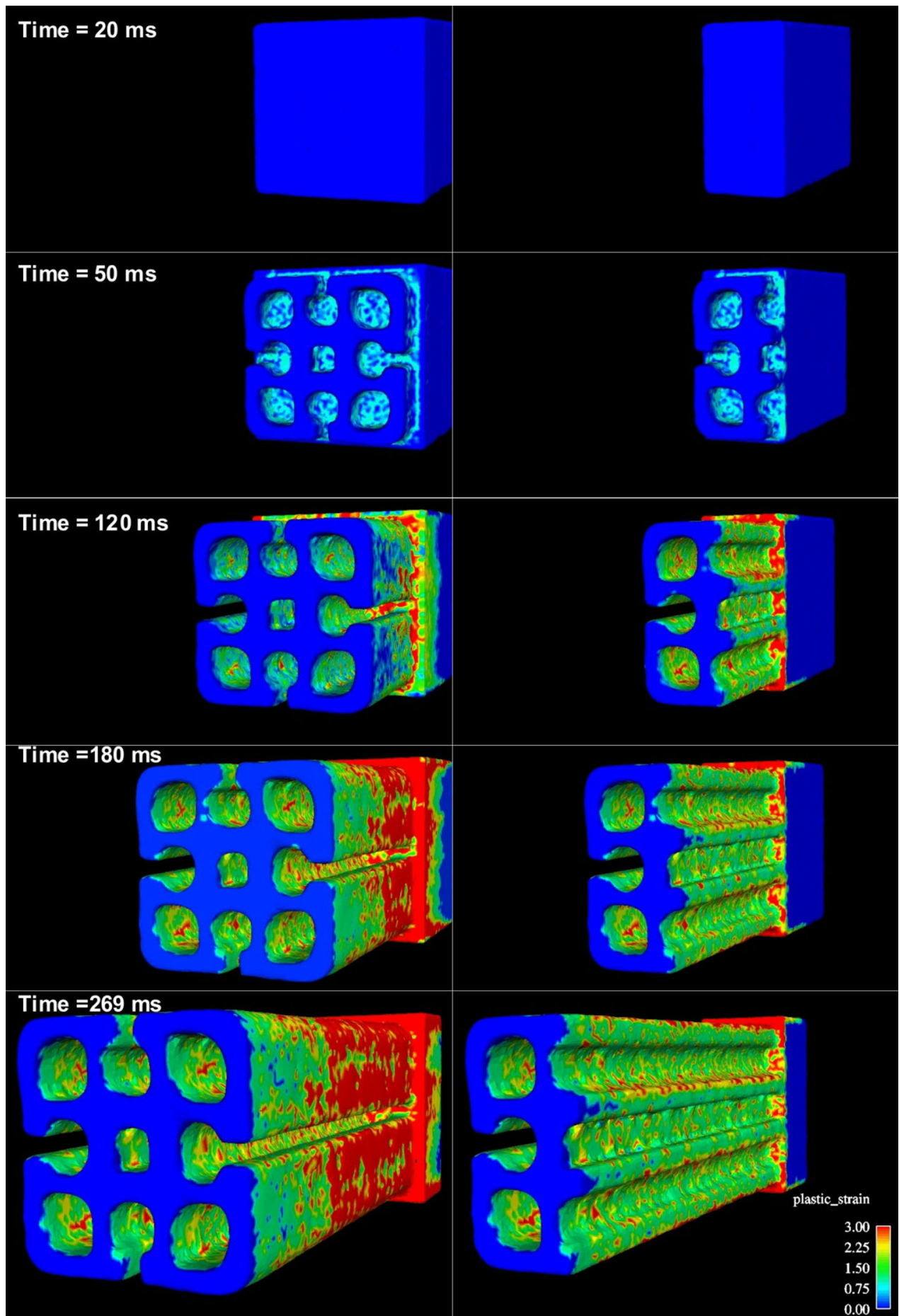

strain then drops off gradually with a $30 \%$ angled decline between 15 and $25 \mathrm{~mm}$ of the product length. The leading edge of the metal experiences the lowest plastic strain. The non-extruded part of the billet is also plastically loaded with peak strain levels of around $30 \%$ on the surface and close to the die exit.

At $120 \mathrm{~ms}$, phase 2 of extrusion has started and the metal close to the die exit begins experiencing higher strain levels of around $300 \%$. There is a larger distribution of plastic strain level in the first $50 \%$ of the extruded metal close to the die orifice. In this first half of the product, strain variations occur over two ranges. Around $90 \%$ of the metal experiences strain between 0 and $80 \%$. This is related to phase 1 where the metal moves as a uniform rigid body. The lower strain levels are within the extruded product. The remaining $10 \%$ of the metal experiences significantly higher strain levels of between 80 and $120 \%$. These higher strain levels are related to phase 2 of extrusion where the metal close to the 

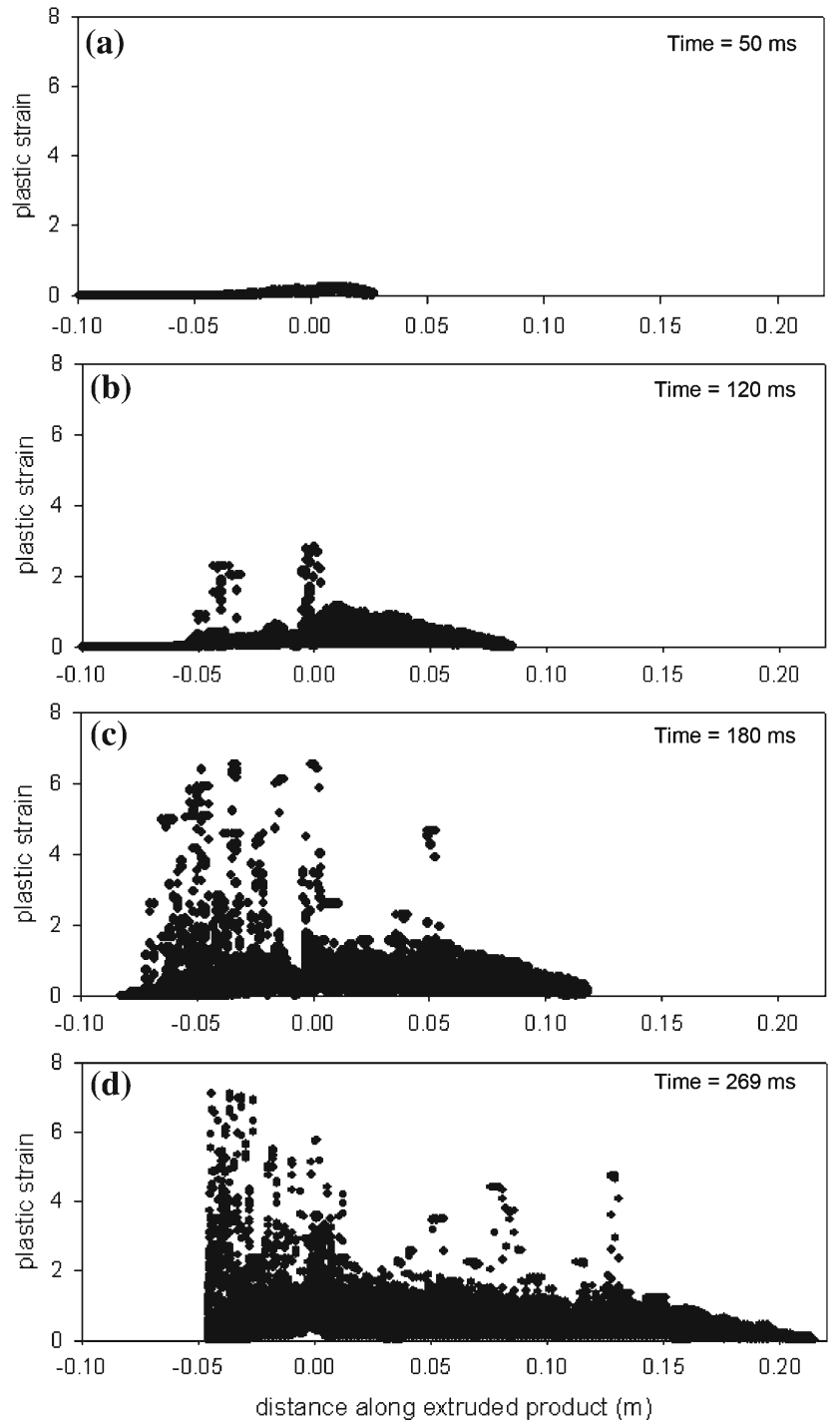

Fig. 14 Variation in plastic strain along the length of the extruded product with time. In the figure the die exit is located at the origin

die exit has experienced high plastic strain and is now flowing through as the extruded product. These occur predominantly on the surface of the extruded billet. Overall the extruded product has strain levels within an envelope of $120 \%$. There is an approximately $30 \%$ angled decline of this plastic strain envelope $40 \mathrm{~mm}$ past the orifice close to the leading edge of the extruded product.

At $180 \mathrm{~ms}$, as the metal gets pushed further through the large die angle exit, very high maximum strain levels of greater than $600 \%$ are experienced by the metal on the surface in the yet to be extruded part. The strain level envelope has increased from $120 \%$ at $120 \mathrm{~ms}$ to almost 250 for $95 \%$ of the extruded product. At the die exit strain levels have reached in excess of $600 \%$. High strain of around $480 \%$ is also experienced on the extruded surface just before the strain level envelope begins its angled decline to the leading edge. This region marks the location at the end of phase 1 extrusion when the free surface influences the internal metal deformation.

At $269 \mathrm{~ms}$ when around $210 \mathrm{~mm}$ of the metal is extruded, the plastic strain profile is similar to the $180 \mathrm{~ms}$ level, albeit with a wider distribution of plastic strain levels in the extruded metal. Progressive extrusion of metal through the die orifice creates additional back pressure in the region close to the orifice resulting in higher strain levels especially on the surface. The point where the high and low surface strain zones meet in the product is a possible location for product failure and would need appropriate annealing treatment.

\subsection{Metal deformation pattern}

In Fig. 15 the billet is shaded in four equal volume horizontal strata. The nature and extent of metal deformation can be determined by analysing the distribution of these colours after extrusion. It also allows the mixing and intermingling of the metal from different initial billet locations to be explored, particularly if there are any compositional variations in the billet. Frames on the left show the surface of the billet and frames on the right show a cross-section through the centre of the metal. At $50 \mathrm{~ms}$, half of the first strata of the billet has passed through the die. The undeformed part of the billet behaves as a single uniformly moving rigid body. At $80 \mathrm{~ms}$ there is visible evidence of distortion of the layers at the edges where the metal is touching the die surface. This region moves more slowly than the remaining billet resulting in a very steep metal deformation profile.

At $150 \mathrm{~ms}$, the entire first strata and about half the second strata have extruded through the die. There is significant stretching and reasonable mixing of the metal layers close to the die orifice on the surface as it is extruded through the complex die shape. This is seen from the mottled colour pattern close to the die orifice. This is consistent with the high levels of plastic strain observed in this region. Internally however, there is limited visible mixing as the interface between the two colours is well defined in the cut section. This suggests that the mixing is restricted to a thin surface region. The bulk of the first stratum has already been completely extruded by this stage. Approximately $10 \%$ of material from this stratum is still left at the back of the die close to the billet surface. At $180 \mathrm{~ms}$ the second stratum of metal has almost extruded through the orifice but one can still clearly see around $10 \%$ of the first stratum trapped at the back close to the die orifice. This indicates a stagnation zone in the convergent section of the flow before the step in the die profile in the flow direction and as predicted by the high plastic strain levels at the back of the die in the previous section.

At $269 \mathrm{~ms}$, three quarters of the metal billet has extruded through the die. There is now material from the first two strata left behind at the back of the die close to the die exit where 
Fig. 15 Deformation profile for extrusion through a complex die. The billet is shaded by four equal volume initial strata. Frames on the right are a section cut across the mid-place of the extruded metal
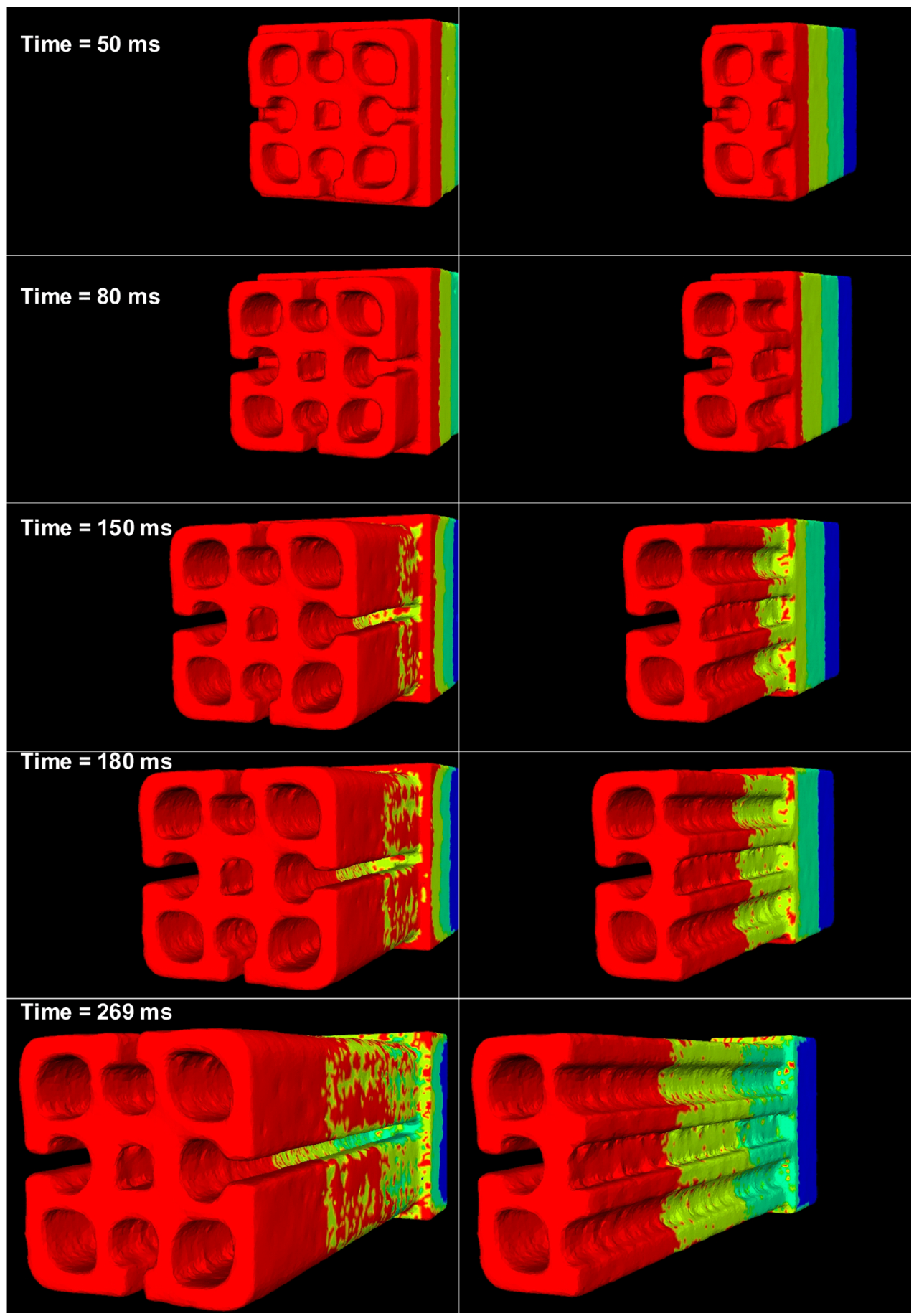

the billet is touching the die surface. This is a result of the large $180^{\circ}$ die angle which leads to a stagnation region at the corners of the die exit. This leads to a defect known as the "funnel" or "pipe" resulting from the non-uniform metal flow. This involves thin layers of metal from early in the billet being deposited in the surface of the extrudate at distances well beyond where the bulk of that material was located. It also creates very high and irregular plastic strains along the surface.

\subsection{Variation in extrusion force}

Figure 16 shows the variation in extrusion force with time for this building product. As the billet pushes forward and starts flowing through the die the extrusion force ramps up rapidly to around $6.8 \mathrm{kN}$. This is when the billet fills the die exit region and becomes fully elastically loaded. The steep increase in the extrusion force is determined by the die orifice configuration. There are very strong oscillations in the 


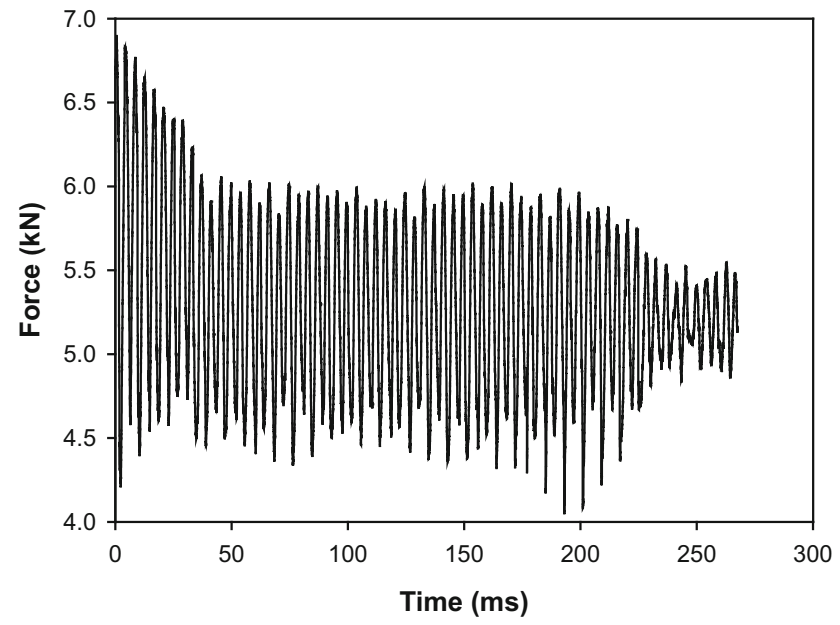

Fig. 16 Variation in punch force (in $\mathrm{kN}$ ) with time during extrusion for a component with a complex cross-section

force with a constant frequency of $150 \mathrm{~Hz}$. The amplitude of these oscillations starts at around $2.5 \mathrm{kN}$ but this later declines to around $1.5 \mathrm{kN}$ after $20 \mathrm{~ms}$. The amplitude then remains almost constant from 20 to $200 \mathrm{~ms}$ before dropping down further to around $1 \mathrm{kN}$ during the final stages of extrusion (phase 3) as the end of the billet approaches the die orifice. As explained earlier for the simpler extrusion case, the oscillations in the force are attributed to stick-slip effects at the die-metal surface resulting from the large extrusion speed and lack of lubrication (or sliding capacity in the SPH boundary condition used). The stick-slip nature of the billet motion was also evident from the large sectional variation in the plastic strain seen in the earlier section.

\section{Conclusion}

The use of the mesh-free elastoplastic SPH method has been explored for modelling metal extrusion. We have shown that the method can simulate deformations for a range of die cross-sections ranging from a simple circular section to a significantly complicated industrial component with a die angle of $180^{\circ}$ which results in significant metal deformation. The metal flow through a tapered die section is easily modelled by SPH and is stable for all extrusion ratios and die angles. The simulation of the complex cross-section demonstrates that SPH has the advantages of being able to follow very high deformations (beyond what is typically possible with FEM and FV methods) especially in geometries where there is large profile and angular variation. Due to its Lagrangian nature it is also able to predict the mixing, stretching and distribution of metal as it is extruded through the die orifice. This provides the ability to keep track of the specific history of each part of the metal allowing fine scale control over the material model and potentially direct prediction of many types of flow and microstructure related defects. The prediction of material distribution in the extruded product is also important in cases where multiple materials are used.

The extrusion process consists of three phases for all cases investigated. This begins with phase 1 where the punch pushes the billet into the tapered die section resulting in a sharp increase in the extrusion force. This is followed by phase 2 where the metal is pushed through the die exit at a uniform rate requiring a constant extrusion force. The process culminates in phase 3 where the rear of the billet approaches the convergent die section with a sharp drop off in the extrusion force.

The effect of changes in die geometry such as the extrusion ratio and die angle on plastic strain, metal deformation profile and maximum extrusion force required has also been explored. Specifically the effects on increased extrusion ratio were found to be:

- There is a strong increase in metal deformation as the extrusion ratio increases from 4 to 16 . The interfaces between deformed metal layers were generally sharp but somewhat uneven due to mixing between the layers. The large deformations at high extrude ratios can lead to increased grain refinement and thereby increased material strength.

- The maximum plastic strain experienced by the extruded metal increases from 220 to over $400 \%$ as the extrusion ratio changes from 4 to 16 .

- A low strain zone exists in the centre of the extruded product only for lower extrude ratios and disappears with an increase in the extrusion ratio from 7.1 to 16 . Such low strain zones can potentially cause chevron crack defects.

- The maximum extrusion force increases sharply with an increase in extrusion ratio, with an increase of around $150 \%$ between extrusion ratios of 4 and 16 . Thus the increased material strength is achieved at the cost of increased power requirements for large extrude ratios.

The effects of increased die angle were found to be:

- There is a reduction in the rate at which the product is extruded due to a stagnation zone created close to the die exit. This can distort the material leading to possible twisting and warping.

- There is only a moderate increase in the plastic strain from a maximum of 220 to $260 \%$ as die angle is increased from 120 to $160^{\circ}$. This occurs only in regions adjacent to the walls of the die exit.

- The plastic strain distribution is higher for larger die angles leading to longer annealing times post extrusion 
suggesting the use of lower die angles for the same extrusion ratio.

- The central low strain zone exists for all three die angles investigated demonstrating that the chevron crack defect is predominantly a function of the extrusion ratio.

- The maximum extrusion force shows only a small increase with die angle giving a variation of around $15 \%$ for die angles between 120 and $160^{\circ}$.

The levels of strain and their distribution can vary significantly depending on the die shape. For the die with a complex cross-section large variations in plastic strain are seen along the length of the extruded product at two scales. These are due to the change in behaviour of the metal as the extrusion progressed from phase 1 to phase 2 . The deformation profile indicated a clear stagnation zone at the back of the die close to the edge consistent with observations made for such die shapes. This stagnation zone leads to a commonly encountered defect known as "funnel" or "pipe" due to non-uniform metal flow. The variation in extrusion force with time is also significantly affected by the shape of the die exit. Large oscillations in the extrusion force are observed and attributed to stick-slip where the billet moves intermittently rather than in a continuous motion. For the complex die cross-section the extrusion force ramps up to its maximum value rapidly and remains at that level almost throughout the extrusion process. This is because of the steep change in the shape of the cross-section for this complex geometry.

\section{References}

1. Alfaro I, Yvonnet J, Cueto E, Chinesta F, Doblare M (2006a) Meshless methods with application to metal forming. Comput Methods Appl Mech Eng 195:6661-6675

2. Alfaro I, Bel D, Cueto E, Doblare M, Chinesta F (2006b) Three dimensional simulation of aluminium extrusion by the $\alpha$ shape based natural element method. Comput Methods Appl Mech Eng 195:4269-4286

3. Bainbridge IF, Nguyen V, Prakash M, Ha J, Grandfield JF, Cleary PW (2007) Modelling of the metal flow during filling of a multiple strand direct chill billet mould table. In: Proceedings: 10th Australasian CastHouse Technology Conference 10: 89-96

4. Bastani AF, Aukrust T, Brandal S (2011) Optimisation of flow balance and isothermal extrusion of aluminium using finite-element simulations. J Materials Proc Tech 211:650-667

5. Chen DC, Syu SK, Wu CH, Lin SK (2007) Investigation into cold extrusion of aluminium billets using three-dimensional finite element method. J Materials Proc Tech 192-193:188-193

6. Chen Y, Wang Q, Peng J, Zhai C, Ding W (2007) Effects of extrusion ratio on the microstructure and mechanical properties of AZ31 Mg alloy. J Materials Proc Tech 182:281-285

7. Cleary P, Ha J, Alguine V, Nguyen T (2002) Flow modelling in casting processes. Appl Math Model 26:171-190

8. Cleary P, Ha J, Prakash M, Nguyen T (2006a) 3D SPH flow predictions and validation for high pressure die casting of automotive components. Appl Math Model 30(11):1406-1427
9. Cleary PW, Prakash M, Ha J (2006b) Novel applications of smoothed particle hydrodynamics (SPH) in metal forming. J Materials Proc Tech 177(1-3):41-48

10. Cleary PW, Prakash M, Ha J, Stokes N, Scott C (2007) Smooth particle hydrodynamics: status and future potential. Prog Comput Fluid Dyn 7:70-90

11. Cleary PW, Das R (2008) The potential for SPH modelling of solid deformation and fracture. In: Reddy D (ed) IUTAM proceedings book series volume: theoretical, modelling and computational aspects of inelastic media. Springer, Vienna, pp 287-296

12. Cleary PW (2010) Elastoplastic deformation during projectile-wall collision. App Math Model 34:266-283

13. Cleary PW, Ha J, Prakash M (2012) Modelling of metal forging using SPH. Appl Math Model 36:3836-3855

14. Das R, Cleary PW (2010) Effect of rock shapes on brittle fracture using Smoothed Particle Hydrodynamics. Theor Appl Fract Mech 53(1):47-60

15. Das R, Cleary PW (2015) Evaluation of the accuracy and stability of the classical SPH method under uniaxial compression. J Sci Comput 52:72-82

16. Fernandez-Mendez S, Bonet J, Huerta A (2005) Continuous blending of SPH with finite elements. Comput Struct 83:1448-1458

17. Gray JP, Monaghan JJ, Swift RP (2001) SPH elastic dynamics. Comput Methods Appl Mech Eng 190:6641-6662

18. Gray JP, Monaghan JJ (2004) Numerical modelling of stress fields and fracture around magma chambers. J Volcanol Geotherm Res 135:259-283

19. Ha J, Cleary P, Alguine V, Nguyen T (1999) Simulation of die filling in gravity die casting using SPH and MAGMAsoft, In: $2^{\text {nd }}$ International Conference on CFD in the Minerals and Process Industries, Melbourne, Australia, pp 423-428

20. Harrison NK, Lamb DB (1982) Extrusion press and method. Columbia University Press, New York (US Patent 4346578 72/271)

21. Komori K (2003) Effect ductile fracture criteria on chevron crack formation and evolution during drawing. Int J Mech Sci 45:141160

22. Kronberger H (1969) Review lecture: hydrostatic extrusion. Proc R Soc Lond 311(1506):331-347

23. Lim LG, Dunne FPE (1997) Modelling central bursting in the extrusion of particulate reinforced metal matrix composite materials. Int J Mach Tools Manuf 37(7):901-915

24. Liu ZS, Swaddiwudhipong S, Koh CG (2004) High velocity impact dynamic response of structures using SPH method. Int J Comput Eng Sci 5:315-326

25. Lu P, Huang S, Jiang K (2013) Numerical analysis for threedimensional bulk metal forming processes with arbitrarily shaped dies using the rigid/visco-plastic element free Galerkin method. Rev Adv Mater Sci 33:416-422

26. Lof J (2000) Developments in finite element simulations of aluminium extrusion, Ph.D. Thesis, University of Twente, Netherlands

27. Monaghan JJ (1992) Smoothed particle hydrodynamics. Ann Rev Astron Astrophys 30:543-574

28. Monaghan JJ (1994) Simulating free surface flows with SPH. J Comp Physiol 110:399-406

29. Monaghan JJ (2000) SPH without a tensile instability. J Comput Phys 159:290-311

30. Prakash M, Cleary PW, Grandfield J, Rohan P, Nguyen V (2007) Optimisation of ingot casting wheel design using SPH simulations. Prog Comput Fluid Dyn 7(2-4):101-110

31. Saanouni K, Mariage JF, Cherouat A, Lestriez P (2004) Numerical prediction of discontinuous central bursting in axisymmetric forward extrusion by continuum damage mechanics. Comput Struct 82:2309-2332

32. Tiernan P, Hillery MT, Dragansecu B, Gheorghe M (2005) Modelling of cold extrusion with experimental variation. J Materials Proc Tech 168:360-366 
33. Wilkins JL (1964) Calculation of elastic-plastic flow. In: Alder B (ed) Methods of computational physics, 8th edn. Academic Press, New York
34. Xiong S, Martins PAF (2006) Numerical solution of bulk metal forming processes by the reproducing kernel particle method. $\mathrm{J}$ Materials Proc Tech 177:49-52 